\title{
Elevated utero/placental GR/NR3C1 is not required for the induction of parturition in the dog
}

\author{
Aykut Gram, Alexandra Trachsel, Alois Boos and Mariusz P Kowalewski \\ Institute of Veterinary Anatomy, Vetsuisse Faculty, University of Zurich, Zurich, Switzerland \\ Correspondence should be addressed to M P Kowalewski; Email: kowalewski@vetanat.uzh.ch
}

\begin{abstract}
The endocrine mechanisms that lead to initiation of parturition in dogs are still not fully understood. The prepartum luteolysis is associated with increased prostaglandin (PG) F2 $\alpha$ secretion; however, there is no pregnancy-or parturition-related increase in estrogens. Moreover, unlike in other mammalian species, in the dog, increased peripartum levels of cortisol measured sporadically in maternal peripheral blood are not mandatory for normal parturition. Nevertheless, auto/paracrine effects of cortisol at the placental feto-maternal level cannot be excluded. Therefore, the aim of this study was to investigate the expression and localization of glucocorticoid receptor (GR/NR3C1) in canine utero/placental (Ut/PI) units and uterine interplacental sites at selected time points during pregnancy (pre-implantation, post-implantation and mid-gestation), and at normal and antigestagen-induced parturition. The Ut/PI expression of GR/NR3C1 did not change significantly from pre-implantation until mid-gestation; however, it was strongly induced during the prepartum luteolysis. Within the interplacental samples, expression of GR/NR3C1-mRNA was greater postimplantation than pre-implantation and did not change afterward, i.e. toward mid-gestation. Compartmentalization studies within the Ut/PI units, involving placenta, endometrium and myometrium separately, performed at the prepartum luteolysis revealed the highest GR/NR3C1-mRNA levels in placenta compared with endometrium and myometrium. Interestingly, in antigestagen-treated midpregnancy dogs, Ut/PI and interplacental GR/NR3C1-mRNA expression remained unaffected. At the cellular level, placental GR/ NR3C1 was clearly detectable in placenta fetalis, i.e. in trophoblast cells. In conclusion, increased expression of GR/NR3C1 during normal parturition, but not following antigestagen-treatment, suggest that it is not required for initiating the signaling cascade of PG synthesis leading to the induction of parturition in the dog.

Reproduction (2016) 152 303-311
\end{abstract}

\section{Introduction}

Cortisol is a steroid hormone produced mainly by the adrenal gland; its production increases in response to stress. Acting via its nuclear receptor subfamily 3 , group C, member 1 (NR3C1 or glucocorticoid receptor; GR), cortisol regulates many reproductive processes including fetal and placental development as well as initiation of parturition (Chida et al. 2011, Li et al. 2014, Wyrwoll 2014). Fetal plasma concentrations of cortisol increase at the end of gestation in several mammalian species, e.g. cattle, sheep and goat, due to maturation of the fetal hypothalamic-pituitary-adrenal axis (Smith et al. 1973, Challis et al. 1977, Flint et al. 1978, Magyar et al. 1980). As also shown in sheep (Mason et al. 1989), glucocorticoids and presumably also increased fetal cortisol levels stimulate the activity of placental cytochrome P450 17 $\alpha$ hydroxylase (CYP17A) and cytochrome P450 (P450arom). This results in a switch of placental steroid production in favor of estrogen, i.e. redirection of steroid synthesis from the delta $(\Delta) 4$ to $\Delta 5$ pathways (Mason et al. 1989). Similar to the sheep, bovine placental CYP17A activity is strongly upregulated at parturition (Schuler et al. 1994, Schuler et al. 2006). Additionally, the role of locally acting steroid sulfatase (STS) in placental production of free, active estrogens from biologically inactive sulfoconjugated estrogens during the prepartal increase in estrogens has been postulated in cattle (Janszen et al. 1995, Greven et al. 2007). The decreased progesterone (P4)/estradiol$17 \beta\left(E_{2}\right)$ ratio causes elevated uterine and myometrial oxytocin receptor (OTR) expression (Larcher et al. 1995, Wu et al. 1996, Helmer et al. 1998, Robinson et al. 2001), which results in increased sensitivity to oxytocin. Oxytocin is capable of inducing uterine synthesis of luteolytic and contractile prostaglandins (PGs) as shown in cattle (Fuchs et al. 1999) and sheep (Meier et al. 1995).

Interestingly, in addition to the above-described roles of cortisol and GR/NR3C1 during initiation of parturition in large animal species, a parallel observation in humans showed that GR/NR3C1 may act as a local placental antigestagen, allowing parturition in women to take place in spite of relatively high circulating P4 levels (Karalis et al. 1996). Furthermore, peripartum cortisol is important for fetal organ development, especially 
maturation of the lung (Bolt et al. 2001, Chida et al. 2011). In mice, GR-knockout results in perinatal death of fetuses, possibly due to lack of surfactant production that is necessary to decrease surface tension at the airliquid interface of the alveoli in the lung (Bolt et al. 2001, Chida et al. 2011).

As for the dog, increased levels of cortisol measured sporadically in maternal peripheral blood peripartum are not mandatory for normal parturition, which generally occurs 63 days after mating, and have been attributed by some authors to maternal stress (Concannon et al. 1978, Hoffmann et al. 1994). In line with this, application of the antigestagen aglepristone to early- and mid-pregnancy dogs did not affect circulating levels of cortisol (Fieni et al. 2001). An important feature of canine reproductive physiology is the lack of placental steroidogenic activity (Hoffmann et al. 1994, Nishiyama et al. 1999). Therefore, the maintenance of pregnancy in this species entirely depends on luteal secretion of P4 (Concannon et al. 1989). The prepartum drop in $\mathrm{P} 4$ concentration is, however, associated with increased placental PGF2 $\alpha$ output (Nohr et al. 1993, Kowalewski et al. 2010). Importantly, in contrast to other domestic animal species, e.g. cattle, in dogs, there is no pregnancy- or parturitionassociated increase in $E_{2}$ concentration (Nohr et al. 1993, Hoffmann \& Schuler 2002). This excludes any possible roles of cortisol and GR/NR3C1 as trigger factors in the placental 'switching mechanism' between the $\Delta 4$ and $\Delta 5$ steroidogenic pathways in dogs. The source of the prepartum PGF $2 \alpha$ seems to be predominantly within the utero/placental compartment $(\mathrm{Ut} / \mathrm{Pl})$, specifically in the fetal trophoblast cells, in which all prostaglandin system members are present (Kowalewski et al. 2010, Gram et al. 2013, Gram et al. 2014b). P4 has a signaling function in the prepartum PGF2 $\alpha$ release, acting at the feto-maternal interface between the trophoblast cells and the maternal stroma-derived decidual cells. The decidual cells are the only cells of the canine placenta expressing progesterone receptor (PGR) (Vermeirsch et al. 2000, Kowalewski 2012) and OTR (Gram et al. 2014a). Interfering with PGR function in these cells, e.g. by applying a receptor-specific blocker (antigestagen), leads to changes in utero-placental PG synthesis similar to those observed during normal prepartum luteolysis, and results in elevated PGF2 $\alpha$ output (Nohr et al. 1993, Kowalewski et al. 2010, Gram et al. 2014a).

Apart from the variable plasma cortisol concentrations found in bitches during spontaneous whelping, no information is available concerning the localization and expression levels of its receptor GR/NR3C1 in canine reproductive tissues. Therefore, possible endocrine effects of cortisol at the feto-maternal level, and their involvement in the process of parturition in dogs, cannot be excluded. Consequently, this study aimed to better understand underlying endocrine mechanisms by investigating the expression and localization of GR/ NR3C1 in canine Ut/PI units and interplacental uterine sites during selected time points of pregnancy, as well as during natural and induced parturition.

\section{Materials and methods}

\section{Animals, tissue collection and preservation}

Tissues were obtained from healthy, cross-breed pregnant bitches (2-8years of age) by ovariohysterectomy (OHE) at selected stages of gestation, as follows: pre-implantation (days $8-12, n=5$ ), post-implantation (days 18-25, $n=5$ ), midgestation (days 35-40, $n=5)$ and prepartum luteolysis $(n=3)$. Additionally, mid-pregnancy dogs (days 40-45 of pregnancy; $n=10$ ) were treated twice with the antigestagen aglepristone in order to selectively block the function of PGR (Alizine, Virbac, Bad Oldesloe, Germany; $10 \mathrm{mg} / \mathrm{kg}$ bw; $2 \times / 24 \mathrm{~h}$ apart); then, tissue samples were collected $24 \mathrm{~h}(n=5)$ and $72 \mathrm{~h}(n=5)$ after the second treatment.

Dogs were mated 2-3 days after ovulation (time needed for oocyte maturation and completion of the first meiotic division), which was determined by vaginal cytology and $\mathrm{P} 4$ measurements $(>5 \mathrm{ng} / \mathrm{mL}$ in peripheral blood). The day of mating was then designated as Day 0 of gestation. The preimplantation stage of gestation was determined by finding freefloating embryos in uterine flushings. The prepartum luteolysis (prepartum progesterone decrease) was assessed by performing regular measurements of circulating P4 concentrations by well-established in-house radioimmunoassay (RIA) after sample extraction with hexane (Hoffmann et al. 1973) every $6 \mathrm{~h}$, starting from Day 58 of pregnancy. Once a steep P4 decline was observed over three consecutive measurements, OHE was performed. The canine placenta, which is classified as endotheliochorial, zonaria (Amoroso 1952, Kehrer 1973), starts to form immediately after implantation, around day 17-18 of embryonal life. Besides the formation of decidua, the strong invasion by trophoblast is associated with the development of marginal hematomas, and formation of the so-called glandular chambers, which are highly enlarged superficial endometrial glands. These establish a thick border layer between the placental labyrinth and the connective tissue covering the deep endometrial glands. Their development continues until around Day 40, when fully developed Ut/PI units are established (Amoroso 1952). Accordingly, samples collected between days 35 and 45 of gestation were referred to as mid-gestation samples in our experiments.

All tissue samples were used for our previous studies (Kowalewski et al. 2010, Gram et al. 2013). Experimental procedures utilizing dogs were performed according to the guidelines of animal welfare legislation and approved by the respective authorities of Justus-Liebig University, Giessen (permit no. II 25.3-19c20-15c Gl 18/14 and VIG3-19c-20/15c Gl 18,14), Giessen, Germany, and the University of Ankara (permit no. Ankara 2006/06), Ankara, Turkey. Respective mean P4 concentrations were previously reported (Kowalewski et al. 2009): $35.71 \pm 7.9 \mathrm{ng} / \mathrm{mL}$ during the pre-implantation period, $29.73 \pm 13.23 \mathrm{ng} / \mathrm{mL}$ post-implantation, $13.32 \pm 8.66 \mathrm{ng} / \mathrm{mL}$ at mid-gestation and $2.07 \pm 0.99 \mathrm{ng} / \mathrm{mL}$ during the prepartum luteolysis. After Alizine treatment, P4 concentrations were as follows (Kowalewski et al. 2009): $15.11 \pm 6.7 \mathrm{ng} / \mathrm{mL}$ before the 
first application; $13.61 \pm 8.2 \mathrm{ng} / \mathrm{mL}$ at the second treatment; $5.1 \pm 2.7 \mathrm{ng} / \mathrm{mL} 24 \mathrm{~h}$ later; $2.33 \pm 1.44 \mathrm{ng} / \mathrm{mL} 48 \mathrm{~h}$ later and $1.2 \pm 0.6 \mathrm{ng} / \mathrm{mL} 72 \mathrm{~h}$ later. No additional serum samples were available for this study.

Following $\mathrm{OHE}$, uterine samples (following implantation, these tissues were referred to as interplacental sites) and utero/placental compartments (the whole thickness of the uterine wall, i.e. uterus with adjacent placenta, comprising placenta fetalis and placenta materna; Ut/PI) were rinsed with phosphate-buffered saline (PBS), trimmed of surrounding connective tissue and preserved for further experiments. The $\mathrm{Ut} / \mathrm{PI}$ units were collected from the middle part of the placental girdle, avoiding marginal hematomas. No interplacental samples collected during prepartum luteolysis were available for the study.

For immunohistochemistry (IHC), tissue samples were fixed by immersion in $10 \%$ neutral phosphate-buffered formalin for $24 \mathrm{~h}$ at $+4{ }^{\circ} \mathrm{C}$ and subsequently washed for 1 week with PBS and embedded in paraffin. For total RNA retrieval, samples were incubated in RNAlater (Ambion Biotechnology $\mathrm{GmbH}$ ) for $24 \mathrm{~h}$ at $+4{ }^{\circ} \mathrm{C}$ and stored at $-80^{\circ} \mathrm{C}$ until further use.

\section{Total RNA isolation and real-time (TaqMan) PCR}

Total RNA was extracted using the standard chloroformisopropanol method with TRIzol reagent (Invitrogen). The total RNA amount and purity in each sample were assessed using a NanoDrop 2000C spectrophotometer (Thermo Fisher Scientific AG). In the next step, DNAse treatment with RQ1 RNase-free DNase (Promega) of total RNA from each tissue was performed according to the supplier's instructions. Reverse transcription (RT) was set up with random hexamers as primers and other reagents from Applied Biosystems by Thermo Fisher Scientific as reported previously (Kowalewski et al. 2006b, Kowalewski et al. 2011). Semiquantitation of canine GR/NR3C1 was performed by real-time (TaqMan) PCR using an automated fluorometer ABI PRISM 7500 Sequence Detection System (Applied Biosystems by Thermo Fisher Scientific). A commercially available gene- and canine species-specific TaqMan system of canine GR/NR3C1 was used, which was purchased from Applied Biosystems (Prod. No. Cf02627498_m1). In order to exclude any potential genomic DNA contamination, PCR reactions were performed with samples that were not reverse-transcribed (the so-called 'minus-RT control'). For an additional control, water was used instead of cDNA. The reaction mixture consisted of $200 \mathrm{nM}$ TaqMan Probe, $300 \mathrm{nM}$ of each primer, $12.5 \mu \mathrm{L}$ Fast Start Universal Probe Master (ROX) (Roche Diagnostics) and $5 \mu \mathrm{L}$ cDNA corresponding to $100 \mathrm{ng}$ total RNA per sample. The thermal cycler setups were as follows: denaturation at $95^{\circ} \mathrm{C}$ for $10 \mathrm{~min}, 40$ cycles at $95^{\circ} \mathrm{C}$ for $15 \mathrm{~s}$ and 1 cycle at $60^{\circ} \mathrm{C}$ for $60 \mathrm{~s}$. The comparative delta CT threshold method $(\Delta \Delta \mathrm{CT})$ was used for quantitation of target gene according to the manufacturer's protocols for the ABI PRISM 7500 Sequence Detection System (Applied Biosystems) and as described previously (Kowalewski et al. 2006b, Kowalewski et al. 2011). The sample with the lowest concentration of the target gene served as the calibrator in the $\triangle \triangle C T$ method. GAPDH, 18SrRNA and CYCLOPHILIN A were used as reference genes for normalization of relative gene expression. The efficiency

www.reproduction-online.org of all TaqMan assays was tested by the CT slope method with a range of 10-fold serial dilutions of the targeted PCR product and using samples from different stages of pregnancy (in order to test the efficiency at different quantities of the targeted RNA expected at different stages of pregnancy) according to the instructions of the manufacturer of the ABI PRISM 7500 Sequence Detector, and was set up to achieve approximately 100\% efficiency. Primer Express software version 2.0 (Applied Biosystems by Thermo Fisher Scientific) was used to design the GAPDH and 18SrRNA primers and probes. The following TaqMan systems including 6-carboxyfluorescein (6-FAM) and 6-carboxytetramethylrhodamine (TAMRA)-labeled TaqMan probes were purchased from Microsynth AG, Balgach, Switzerland: GAPDH forward 5'-GCT GCC AAA TAT GAC GAC ATC A-3', reverse: 5'-GTA GCC CAG GAT GCC TTT GAG-3', TaqMan probe 5'-TCC CTC CGA TGC CTG CTT CAC TAC CTT-3' (GenBank: AB028142; product length: $75 \mathrm{bp}) ; 18 \mathrm{SrRNA}$ forward 5'-GTC GCT CGC TCC TCT CCT ACT-3', reverse 5'-GGC TGA CCG GGT TGG TTT-3', TaqMan probe 5'-ACA TGC CGA CGG GCG CTG AC-3' (GenBank: FJ797658; product length: $125 \mathrm{bp})$. For $G R / N R 3 C 1$, as well as for CYCLOPHILIN A, a commercially available gene-specific TaqMan system was purchased from Applied Biosystems (Prod. No. Cf03986523_gH).

\section{Compartmentalization of utero/placental GR/NR3C1- mRNA expression during prepartum luteolysis}

Under sterile conditions, two tissue sections (5 $\mu \mathrm{m}$ each) of formalin-fixed, paraffin-embedded Ut/PI units from the prepartum luteolysis group were cut with a microtome and placed on Arcturus PEN Membrane Glass slides (Applied Biosystems). Sections were dried overnight at $37^{\circ} \mathrm{C}$. Thereafter, slides were dewaxed in xylene, rehydrated in graded ethanol and stained with hematoxylin to distinguish each tissue layer (i.e. placenta, endometrium and myometrium) for dissection. Due to the structural characteristics of the strongly invasive endotheliochorial placenta of the dog, the dissected placental compartments comprised both maternal and fetal parts of the organ. Following air-drying, dissection was performed using a sterile scalpel blade under a stereomicroscope at $50 \times$ magnification. The separated tissue fragments were then transferred into sterile Eppendorf tubes, and total RNA was immediately extracted using the RNeasy FFPE kit (Qiagen) following the manufacturer's instructions and as described previously (Gram et al. 2014a).

\section{Immunohistochemical staining}

Immunohistochemical (IHC) staining was performed using our previously described method (Kowalewski et al. 2006a,b). Briefly, formalin-fixed tissue samples were embedded in paraffin, cut into $2-3 \mu \mathrm{m}$ thick slices, mounted on Super Frost microscope slides (Menzel-Glaeser, Braunschweig, Germany), dewaxed in xylene and rehydrated through graded ethanol solutions to water. Afterward, sections were immersed in $10 \mathrm{mM}$ citrate buffer $\mathrm{pH} 6.0$ and heated in a microwave oven at $560 \mathrm{~W}$ for $15 \mathrm{~min}$ to retrieve antigens. Endogenous peroxidase activity was quenched by treating slides with $0.3 \%$ hydrogen peroxide in methanol for $30 \mathrm{~min}$ on a shaker at

Reproduction (2016) 152 303-311 
ambient temperature. Afterward, in order to avoid background staining, slides were incubated with $10 \%$ normal serum from the same species in which the secondary antibody was made.

The following primary antibodies were used: monoclonal mouse anti-rat GR/NR3C1 IgG2, dilution 1:300 (LSBio Inc, Seattle, WA, USA); monoclonal mouse anti-VIMENTIN IgG2a (M7020; Clone 3B4), dilution 1:100 (Dako Schweiz AG); affinity-purified polyclonal rabbit anti-CYTOKERATIN, wide spectrum screening, dilution 1:300 (Dako Schweiz). The primary antibodies were diluted in IHC buffer/0.3\% Triton X, $\mathrm{pH}$ 7.2-7.4 (0.8 mM Na $2 \mathrm{HPO}_{4}, 1.47 \mathrm{mM} \mathrm{KH}_{2} \mathrm{PO}_{4}, 2.68 \mathrm{mM}$ $\mathrm{KCl}, 137 \mathrm{mM} \mathrm{NaCl}$ ) and incubated overnight at $4^{\circ} \mathrm{C}$. For isotype controls, instead of the primary antibody, sections were overlaid with irrelevant, nonimmune antibodies at the same protein concentration as for primary antibodies: mouse IgG2a (Dako Schweiz) for GR/NR3C1 and VIMENTIN, or rabbit IgG for CYTOKERATIN (I-1000; Vector Laboratories, Burlingame, CA, USA). Slides were subsequently rinsed with IHC buffer $/ 0.3 \%$ Triton $X$ buffer in order to remove unbound primary antibody and incubated with biotinylated secondary antibodies: horse anti-mouse IgG BA2000 or goat anti-rabbit IgG BA1000, both at 1:100 dilution (Vector Laboratories, Burlingame, CA, USA). After rinsing, a streptavidin-peroxidase Vectastain $\mathrm{ABC}$-peroxidase kit was applied to the biotinylated secondary antibody, according to the manufacturer's instructions (Vector Laboratories, Burlingame, CA, USA). Color development was achieved with a Liquid DAB + substrate kit (Dako Schweiz AG). Then, slides were washed in running tap water, counter-stained in hematoxylin, dehydrated in a graded ethanol series and xylene and finally mounted in Histokit (Assistant, Osterode, Germany).

\section{Statistics}

Statistical analysis was performed for the evaluation of realtime (TaqMan) PCR data. One-way ANOVA was performed followed by the Tukey-Kramer multiple comparisons posttest in order to determine the effect of pregnancy stage on GR/NR3C1 expression at selected time points during pregnancy. Dunnett's multiple comparison test was applied to reveal significance among levels of GR/NR3C1 expression after aglepristone-induced luteolysis; the results show the $n$-fold change in target gene expression compared with its expression at mid-gestation.

The relative levels of GR/NR3C1-mRNA expression in the different dissected tissue compartments (i.e. placenta, endometrium and myometrium) of the utero/placental units during prepartum luteolysis were assessed by pairwise, unpaired, two-tailed Student's t-test. The statistical software program GraphPad 3.06 (GraphPad Software) was used for all tests. Numerical data are presented as the mean \pm S.D.

\section{Results}

\section{Expression of GR/NR3C1-mRNA in canine utero/placental units and interplacental uterine sites during pregnancy, and during natural prepartum luteolysis and aglepristone-induced abortion}

Expression of GR/NR3C1-mRNA was detectable in Ut/PI units and interplacental samples at all pregnancy
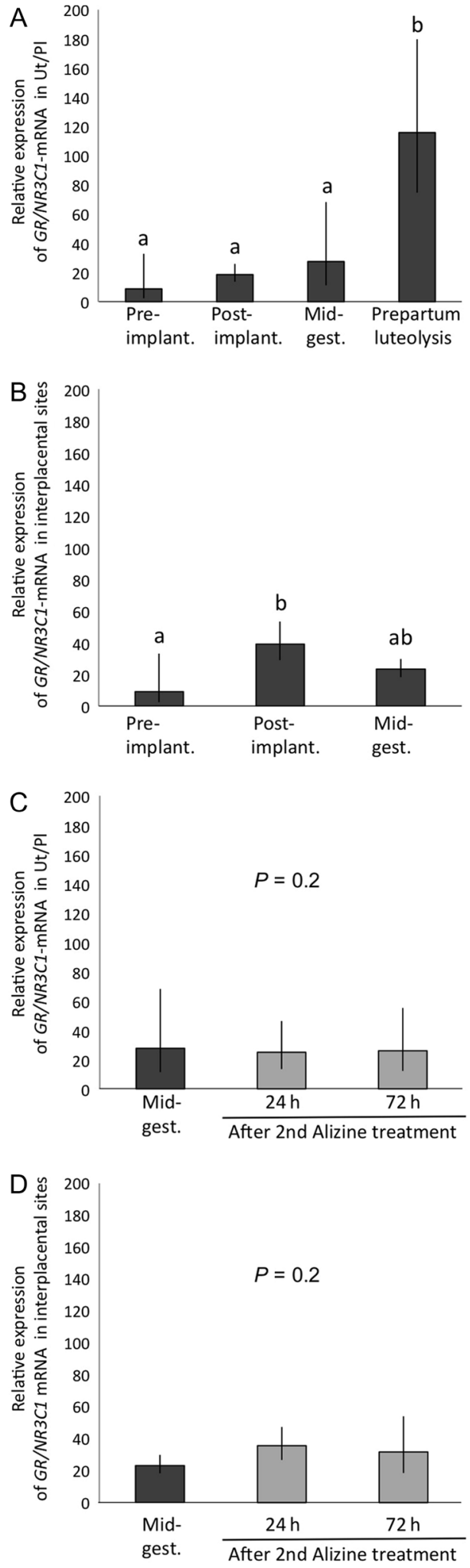

Figure 1 Expression of GR/NR3C1-mRNA as determined by real-time (TaqMan) PCR (mean \pm S.D.) in canine Ut/PI compartments (A) and interplacental uterine sites (B) during pregnancy and aglepristoneinduced parturition (C and D). Bars with different letters differ at $P<0.01$ in (A) or at $P<0.05$ in (B). ((C) and (D) Compared with the mid-pregnancy group as a nontreated control). 
stages examined (Fig. 1A). The Ut/PI mRNA expression was low from the pre-implantation stage of pregnancy until mid-gestation (Fig. 1A). Afterward, before parturition, i.e. during the prepartum luteolysis, a significant increase $(P<0.01)$ was detected (Fig. 1A). Within the interplacental tissues, expression of GR/NR3C1-mRNA increased significantly $(P<0.05)$ from the pre-implantation to post-implantation stage and did not change significantly $(P>0.05)$ during midgestation (Fig. 1B).

For experiments investigating the expression of $G R /$ $N R 3 C 1$ during antigestagen-induced parturition/abortion on days 40-45 of gestation, samples collected from midpregnancy dogs were used in the Dunnett's multiple comparison test as nontreated controls. However, the expression of GR/NR3C1 remained unaffected $(P=0.2)$ in response to aglepristone treatment in both kinds of tissues, i.e. in the Ut/PI units and at interplacental sites (Fig. 1C and D).

\section{Compartmentalization of utero/placental GR/NR3C1- mRNA expression during prepartum luteolysis}

The expression of GR/NR3C1-mRNA within the three dissected tissue layers (i.e. placenta, endometrium and myometrium) of canine Ut/PI units during prepartum luteolysis (Fig. 2) showed highest levels in the placental layer, compared with myometrium $(P=0.02)$ and endometrium $(P=0.03)$. No statistically significant difference was noted between myometrial and endometrial GR/NR3C1-mRNA levels $(P=0.62)$ (Fig. 2).

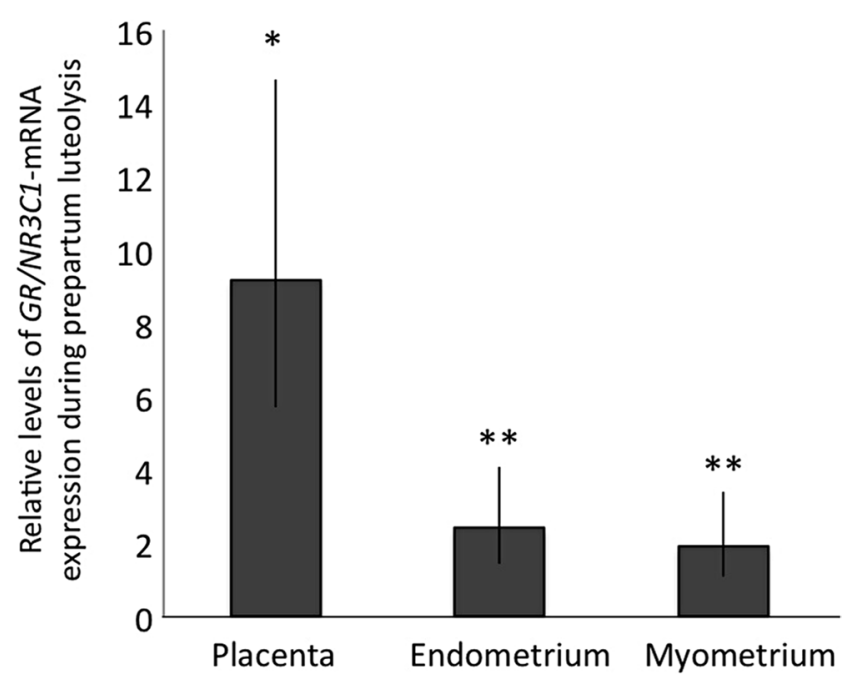

Figure 2 Compartmentalization of GR/NR3C1-mRNA expression in the canine utero/placental compartment during prepartum luteolysis as determined by real-time (TaqMan) PCR (mean \pm s.D.). Bars with different asterisks differ at $P=0.03$ between placenta and endometrium, and at $P=0.02$ between placenta and myometrium.

\section{Immunolocalization of GR/NR3C1 in canine utero/placental units}

As determined by IHC, the expression of GR/NR3C1 protein was clearly localized to the endometrial luminal/surface epithelial cells and superficial glands (Fig. 3A), including the so-called glandular chambers at placentation sites, and to myometrium (Fig. 3B, C and $D)$. The endometrial signals appeared weaker in deep uterine glands (Fig. 3B). These expression patterns of endometrial and myometrial GR/NR3C1 did not change throughout gestation both in $\mathrm{Ut} / \mathrm{PI}$ units and at the interplacental sites. Within the placental labyrinth, GR/ NR3C1 was clearly detectable in fetal trophoblast cells throughout the placentation period as well as during prepartum luteolysis (Fig. 3E and 3H). Sporadically, only weak or no signals were detected in maternal stroma-derived decidual cells (Fig. 3E and H). For easier differentiation of cells within the canine placenta (i.e. endothelial, trophoblast and decidual cells), epithelial cell-specific anti-CYTOKERATIN (wide spectrum, pancytokeratin; Fig. 3F and I) and mesenchyme cell-specific anti-VIMENTIN (Fig. 3G and J) staining was performed on two consecutive sections following those used for GR/NR3C1 detection.

\section{Discussion}

In the dog, the prepartum PGF $2 \alpha$ release is only sporadically associated with increased cortisol levels in maternal peripheral blood (Concannon et al. 1978, Hoffmann et al. 1994). Possible local, i.e. utero-placental effects, cannot, however, be ruled out. Therefore, aiming to determine possible autocrine/paracrine effects of glucocorticoids during canine gestation, in this study, we investigated the time-dependent expression and localization of GR/ NR3C1 in tissues of canine uterus and placenta collected at selected stages of pregnancy. Tissue samples were examined spanning the time-frame from pre-implantation until mid-gestation, as well as during normal and antigestagen-induced luteolysis. Following more or less constant expression until mid-gestation, utero-placental levels of GR/NR3C1 increased greatly during the prepartum luteolysis. This increase must originate predominantly in the fetal compartments of the placenta, i.e. in the trophoblast cells, as revealed in our experiments investigating both the compartmentalization of mRNA expression and IHC staining.

These findings corroborate observations made in other species, e.g. in sheep and humans, in which similar spatio-temporal expression patterns of GR/NR3C1 were seen before parturition (Driver et al. 2001, Gupta et al. 2003, Mparmpakas et al. 2014). Together with the increased levels of cortisol observed in the fetal and maternal plasma of these species, 

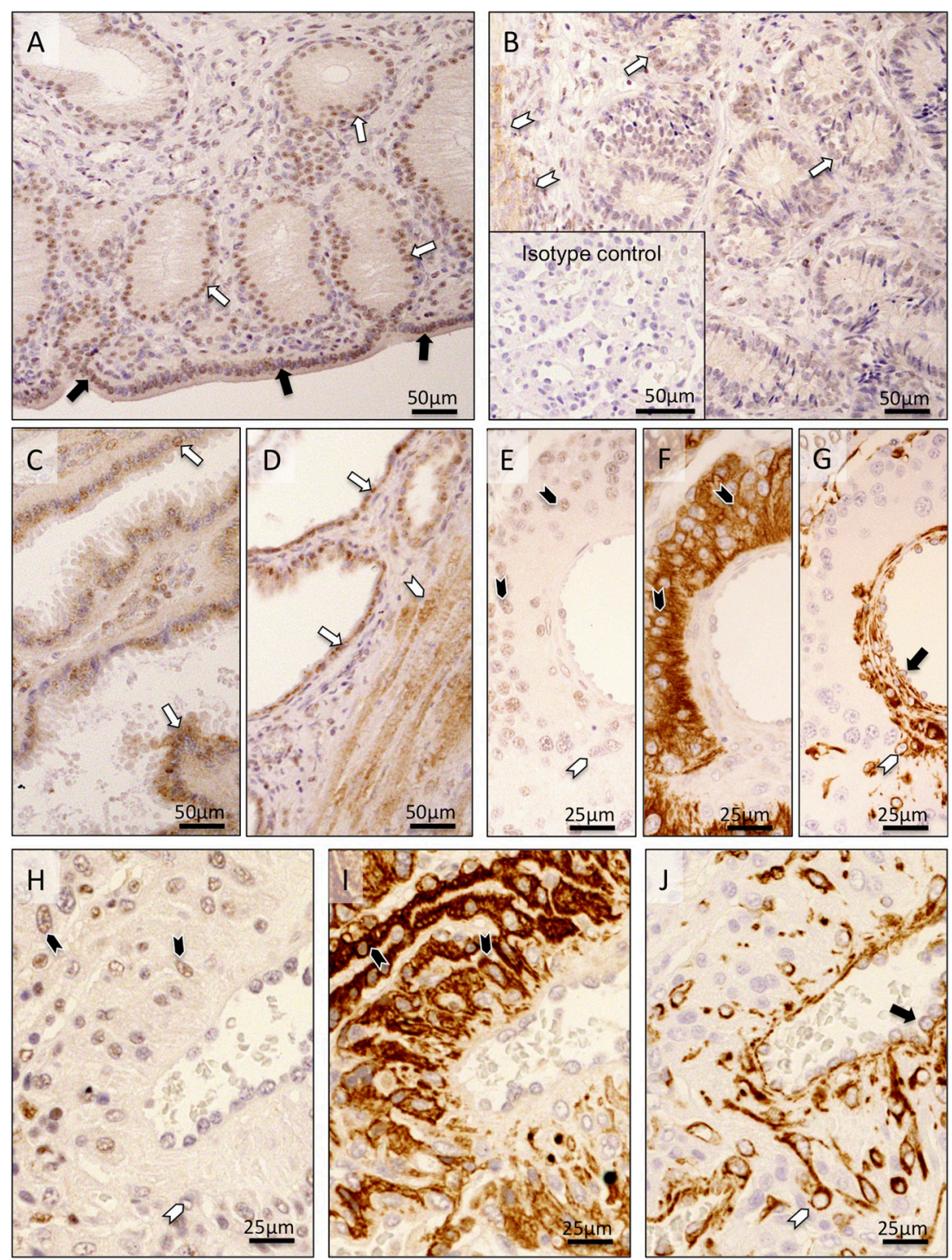

Figure 3 Immunohistochemical (IHC) localization of glucocorticoid receptor (GR/NR3C1) in the canine uterine and utero/placental (Ut/PI) compartments at selected time points during pregnancy. At the preimplantation stage (A and B), in the Ut/PI units during mid-gestation $(\mathrm{C}, \mathrm{D}$ and $\mathrm{E})$ and in the $\mathrm{Ut} /$ $\mathrm{Pl}$ compartments at prepartum luteolysis $(\mathrm{H})$. (A and B) At pre-implantation, nuclear staining of GR/NR3C1 is predominantly localized to the endometrial luminal (surface) epithelial cells (solid arrows in A), glandular epithelial cells of the superficial uterine glands (open arrows in A) and myocytes (open arrowheads in B). The signals in deep uterine glands appear weaker than in superficial glands (open arrows in B). During mid-gestation, within the Ut/PI units, endometrial GR/NR3C1 expression is detected in the superficial glands (the so-called glandular chambers) and deep uterine glands (open arrows in C and D, respectively), and myometrium (open arrowhead in D). In the placental labyrinth during mid-gestation, signals are localized in fetal trophoblast cells (solid arrowheads in E). At prepartum luteolysis, fetal trophoblast cells stain strongly (solid arrowheads in $\mathrm{H}$ ). No, or sporadically only weak, signals can be identified in maternal decidual cells (open arrowhead in $\mathrm{E}$ and $\mathrm{H}$ ). In order to distinguish between fetal and maternal cell types within the canine placenta, i.e. endothelial, trophoblast and decidual cells, (pan)CYTOKERATIN (wide spectrum) and VIMENTIN staining was performed in consecutive sections following those used for GR/NR3C1. Trophoblast cells stain positively for CYTOKERATIN (solid arrowheads in F and I), whereas endothelial cells (solid arrows in $\mathrm{G}$ and $\mathrm{J}$ ) and decidual cells (open arrowheads in $G$ and J) stain positively for VIMENTIN. There is no background staining in the isotype control (inserted in B).
GR/NR3C1 plays an important role in modulating uteroplacental steroid synthesis in favor of estrogens, e.g. in sheep and cattle (Mason et al. 1989, Schuler et al. 1994, 2006). This applies also to the human placenta, which, albeit lacking $17 \alpha \mathrm{HSD}$ activity, is equipped with other endocrine mechanisms facilitating upregulation of estrogen production close to and at term (reviewed in (Kota et al. 2013)). Due to the lack of placental steroids and prepartum estrogen increase, no such causality can, however, exist for the dog. Importantly, the prepartum luteolysis, besides being characterized by steeply decreasing P4 concentrations, is also associated with diminishing levels of circulating $E_{2}$, further indicating the luteal origin of both steroids (Hoffmann et al. 1994, Onclin et al. 2002). In this respect, in dogs, like in most other mammalian species, e.g. rabbits, mice, rats, goats, pigs or cattle, P4 withdrawal is required for initiation of parturition (Ash \& Heap 1975, Sugimoto et al. 1997, Brown et al. 2004, Zakar \& Hertelendy 2007, Ratajczak \&
Muglia 2008). This strongly contrasts with the endocrine milieu observed during parturition in guinea pigs, humans and most other primates that maintain high P4 plasma levels during parturition (Heap \& Deanesly 1966, Karalis et al. 1996, Nnamani et al. 2013). Interestingly, however, as shown in vitro in the human term placenta model, GR/NR3C1 might antagonize the action of P4 in the placenta by acting as a local antigestagen at the end of pregnancy and thereby facilitating the prepartum endocrine cascade (Karalis et al. 1996). GR/NR3C1 and PGR can bind to the same recognition site in promoters of target genes (von der Ahe et al. 1985). However, while P4 binds to GR/NR3C1 with $25-50 \%$ of the affinity of cortisol (Philibert et al. 1991) and $12-42 \%$ of the affinity of synthetic glucocorticoid dexamethasone (Ojasoo et al. 1988), cortisol at physiological concentrations does not bind to PGR (Ojasoo et al. 1988). Taking into account the increased expression of GR/NR3C1 in the canine placenta during prepartum luteolysis, and 
the lack of placental steroids, functional competition between PGR and GR/NR3C1 for P4 binding could also apply in the dog, especially since no other local withdrawal mechanisms of $\mathrm{P} 4$ are known in this species. At the cellular level, as presented herein, this putative endocrine mechanism would involve competition between fetal trophoblast, where the GR/NR3C1 is localized, and maternal decidual cells expressing PGR. This hypothesis, while it still needs to be validated, might explain the observation of variable, lower progesterone concentrations at the end of canine gestation during the initiation of parturition (Concannon et al. 1975, 1989, Concannon \& Hansel 1977). Noteworthy, regrettably, no additional serum samples were available to this study that would allow determination and correlation of GR/NR3C1 expression levels with circulating peripheral cortisol levels, especially at the time of prepartum luteolysis.

As shown in our previous studies, inhibition of PGR function by the antigestagen aglepristone in midpregnancy dogs results in activation of the placental PG system and, unequivocally, leads to preterm luteolysis/ abortion (Kowalewski et al. 2010, Kowalewski 2014, Gram et al. 2014a). This further emphasizes the important signaling role of $\mathrm{P} 4$ in the endocrine cascade leading to initiation of parturition in the dog. Locally, aglepristone treatment results in suppression of uterine but not placental PGR expression, whereas both uterine and placental OTR levels become strongly upregulated (Kowalewski et al. 2010, Kowalewski 2014, Gram et al. 2014a). The spatio-temporal expression pattern of OTR within the canine uterus and placenta clearly indicates its involvement in the prepartum signaling cascade in this species.

In this context, one of the most important observations from this study is the unaltered uterine and placental expression of GR/NR3C1 following application of an antigestagen. Notably, an aglepristone-related antigestagen, mifepristone, was shown to act as an agonist/antagonists of GR/NR3C1 (Zhang et al. 2007). The degree of its glucocorticoid agonist activity depends on the concentration of GR/NR3C1 in the cell, and increases with the presence of the receptor (Zhang et al. 2007). Even though mifepristone has a very similar molecular structure to aglepristone (Hoffmann \& Schuler 2002), there is no information currently available on aglepristone-binding capacity of GR/NR3C1.

Regardless, however, the unaltered expression of $G R / N R 3 C 1$ in antigestagen-treated dogs suggests that its upregulated expression and presumably increased functionality are not needed to initiate the prepartum luteolytic cascade in dogs.

In conclusion, for the first time, our study reveals the uterine and placental expression of GR/NR3C1 at selected time points during canine pregnancy and at normal and antigestagen-induced parturition. We introduce GR/NR3C1 as a new and possibly important player involved in the placental cross-talk between maternal decidual cells and fetal trophoblast in the canine term placenta. Importantly, especially when the unaltered expression of the receptor during induced luteolysis is considered, other roles of GR/NR3C1 in the prepartum endocrine cascade in the dog need to be taken into account, e.g. including those involved in local, i.e. placental, functional withdrawal of P4.

\section{Declaration of interest}

The authors declare that there is no conflict of interest that could be perceived as prejudicing the impartiality of the research reported. All authors read and approved the final version of the manuscript.

\section{Funding}

This research was supported by the Swiss National Science Foundation (SNSF); research grant number 31003A_160251.

\section{Acknowledgements}

Authors are grateful to Prof Dr Selim Aslan, Near East University, Cyprus (formerly of the University of Ankara, Turkey), and Prof Dr Bernd Hoffmann, Justus-Liebig University Giessen, Germany, and their teams for provision of the tissue material, and to Dr Barry Bavister for careful editing of the manuscript. The technical expertise and contributions of Elisabeth Högger is greatly appreciated.

\section{References}

Amoroso EC 1952 Placentation. In Marshall's Physiology of Reproduction, pp 127-316. Ed AS Parkers. London, UK: Longmans Green.

Ash RW \& Heap RB 1975 Estrogen, progesterone and corticosteroid concentrations in peripheral plasma of sows during pregnancy, parturition, lactation and after weaning. Journal of Endocrinology 64 141-154. (doi:10.1677/joe.0.0640141)

Bolt RJ, van Weissenbruch MM, Lafeber HN \& Delemarre-van de Waal HA 2001 Glucocorticoids and lung development in the fetus and preterm infant. Pediatric Pulmonology 32 76-91. (doi:10.1002/ppul.1092)

Brown AG, Leite RS \& Strauss JF 2004 Mechanisms underlying "functional" progesterone withdrawal at parturition. Uterus and Human Reproduction 1034 36-49. (doi:10.1196/annals.1335.004)

Challis JR, Kendall JZ, Robinson JS \& Thorburn GD 1977 The regulation of corticosteroids during late pregnancy and their role in parturition. Biology of Reproduction 16 57-69. (doi:10.1095/biolreprod16.1.57)

Chida D, Miyoshi K, Sato T, Yoda T, Kikusui T \& Iwakura Y 2011 The role of glucocorticoids in pregnancy, parturition, lactation, and nurturing in melanocortin receptor 2-deficient mice. Endocrinology 152 1652-1660. (doi:10.1210/en.2010-0935)

Concannon PW \& Hansel W 1977 Prostaglandin-F2alpha induced luteolysis, hypothermia, and abortions in beagle bitches. Prostaglandins 13 533-542. (doi:10.1016/0090-6980(77)90030-2)

Concannon PW, Hansel W \& Visek WJ 1975 The ovarian cycle of the bitch: plasma estrogen, $\mathrm{LH}$ and progesterone. Biology of Reproduction 13 112-121. (doi:10.1095/biolreprod13.1.112)

Concannon PW, Butler WR, Hansel W, Knight PJ \& Hamilton JM 1978 Parturition and lactation in the bitch: serum progesterone, cortisol and prolactin. Biology of Reproduction 19 1113-1118. (doi:10.1095/ biolreprod19.5.1113) 
Concannon PW, McCann JP \& Temple M 1989 Biology and endocrinology of ovulation, pregnancy and parturition in the dog. Journal of Reproduction and Fertility. Supplement 39 3-25.

Driver PM, Kilby MD, Bujalska I, Walker EA, Hewison M \& Stewart PM 2001 Expression of 11 beta-hydroxysteroid dehydrogenase isozymes and corticosteroid hormone receptors in primary cultures of human trophoblast and placental bed biopsies. Molecular Human Reproduction 7 357-363. (doi:10.1093/molehr/7.4.357)

Fieni F, Martal J, Marnet PG, Siliart B, Bernard F, Riou M, Bruyas JF \& Tainturier D 2001 Hormonal variation in bitches after early or mid-pregnancy termination with aglepristone (RU534). Journal of Reproduction and Fertility. Supplement 57 243-248.

Flint AP, Kingston EJ, Robinson JS \& Thorburn GD 1978 Initiation of parturition in the goat: evidence for control by foetal glucocorticoid through activation of placental C21-steroid 17alpha-hydroxylase. Journal of Endocrinology 78 367-378. (doi:10.1677/joe.0.0780367)

Fuchs AR, Rust W \& Fields MJ 1999 Accumulation of cyclooxygenase-2 gene transcripts in uterine tissues of pregnant and parturient cows: stimulation by oxytocin. Biology of Reproduction 60 341-348. (doi:10.1095/biolreprod60.2.341)

Gram A, Buchler U, Boos A, Hoffmann B \& Kowalewski MP 2013 Biosynthesis and degradation of canine placental prostaglandins: prepartum changes in expression and function of prostaglandin F2alpha-synthase (PGFS, AKR1C3) and 15-prostaglandin dehydrogenase. Biology of Reproduction 89 1821-1825. (doi:10.1095/ biolreprod.113.109918)

Gram A, Boos A \& Kowalewski MP 2014a Uterine and placental expression of canine oxytocin receptor during pregnancy and normal and induced parturition. Reproduction in Domestic Animals 49 (Supplement 2) 41-49. (doi:10.1111/rda.12295)

Gram A, Fox B, Buchler U, Boos A, Hoffmann B \& Kowalewski MP 2014b Canine placental prostaglandin E2 synthase: expression, localization, and biological functions in providing substrates for prepartum PGF2alpha synthesis. Biology of Reproduction 91 154. (doi:10.1095/ biolreprod.114.122929)

Greven H, Kowalewski MR, Hoffmann B, Geyer J, Rex-Haffner M, Ugele B \& Schuler G 2007 Bovine placental steroid sulphatase: molecular cloning and expression pattern in placentomes during gestation and at parturition. Placenta 28 889-897. (doi:10.1016/j.placenta.2007.01.008)

Gupta S, Gyomorey S, Lye SJ, Gibb W \& Challis JR 2003 Effect of labor on glucocorticoid receptor (GR(Total), GRalpha, and GRbeta) proteins in ovine intrauterine tissues. Journal of the Society for Gynecologic Investigation 10 136-144. (doi:10.1016/S1071-5576(03)00010-8)

Heap RB \& Deanesly R 1966 Progesterone in systemic blood and placentae of intact and ovariectomized pregnant guinea-pigs. Journal of Endocrinology 34 417-423. (doi:10.1677/joe.0.0340417)

Helmer H, Hackl T, Schneeberger C, Knofler M, Behrens O, Kaider A \& Husslein P 1998 Oxytocin and vasopressin 1a receptor gene expression in the cycling or pregnant human uterus. American Journal of Obstetrics and Gynecology 179 1572-1578. (doi:10.1016/S00029378(98)70027-4)

Hoffmann B \& Schuler G 2002 The bovine placenta; a source and target of steroid hormones: observations during the second half of gestation. Domestic Animal Endocrinology 23 309-320. (doi:10.1016/S07397240(02)00166-2)

Hoffmann B, Kyrein HJ \& Ender ML 1973 An efficient procedure for the determination of progesterone by radioimmunoassay applied to bovine peripheral plasma. Hormone Research 4 302-310. (doi:10.1159/000178317)

Hoffmann B, Hoveler R, Nohr B \& Hasan SH 1994 Investigations on hormonal changes around parturition in the dog and the occurrence of pregnancy-specific non conjugated oestrogens. Experimental and Clinical Endocrinology 102 185-189. (doi:10.1055/s-0029-1211280)

Janszen BPM, Bevers MM, Vantol HTM, Dieleman SJ, Vanderweijden GC \& Taverne MAM 1995 Estrogen sulfatase activity in endometrium and fetal membranes of late gestational and parturient cows. Animal Reproduction Science 37 251-256. (doi:10.1016/0378-4320(94)01344-L)

Karalis K, Goodwin G \& Majzoub JA 1996 Cortisol blockade of progesterone: a possible molecular mechanism involved in the initiation of human labor. Nature Medicine 2 556-560. (doi:10.1038/ nm0596-556)
Kehrer A 1973 [Chorionic development and structure of the placenta zonaria in the cat, dog and fox (author's transl)]. Zeitschrift fur Anatomie und Entwicklungsgeschichte 143 25-42. (doi:10.1007/BF00519908)

Kota SK, Gayatri K, Jammula S, Kota SK, Krishna SV, Meher LK \& Modi KD 2013 Endocrinology of parturition. Indian Journal of Endocrinology and Metabolism 17 50-59.

Kowalewski MP 2012 Endocrine and molecular control of luteal and placental function in dogs: a review. Reproduction in Domestic Animals 47 (Supplement 6) 19-24. (doi:10.1111/rda.2012.47.issue-s6)

Kowalewski MP 2014 Luteal regression vs. prepartum luteolysis: regulatory mechanisms governing canine corpus luteum function. Reproductive Biology 14 89-102. (doi:10.1016/j.repbio.2013.11.004)

Kowalewski MP, Mason JI, Howie AF, Morley SD, Schuler G \& Hoffmann B 2006a Characterization of the canine 3beta-hydroxysteroid dehydrogenase and its expression in the corpus luteum during diestrus. Journal of Steroid Biochemistry and Molecular Biology $101254-262$. (doi:10.1016/j.jsbmb.2006.06.029)

Kowalewski MP, Schuler G, Taubert A, Engel E \& Hoffmann B 2006b Expression of cyclooxygenase 1 and 2 in the canine corpus luteum during diestrus. Theriogenology 66 1423-1430. (doi:10.1016/j. theriogenology.2006.01.039)

Kowalewski MP, Beceriklisoy HB, Aslan S, Agaoglu AR \& Hoffmann B 2009 Time related changes in luteal prostaglandin synthesis and steroidogenic capacity during pregnancy, normal and antiprogestin induced luteolysis in the bitch. Animal Reproduction Science 116 129-138. (doi:10.1016/j. anireprosci.2008.12.011)

Kowalewski MP, Beceriklisoy HB, Pfarrer C, Aslan S, Kindahl H, Kucukaslan I \& Hoffmann B 2010 Canine placenta: a source of prepartal prostaglandins during normal and antiprogestin-induced parturition. Reproduction 139 655-664. (doi:10.1530/REP-09-0140)

Kowalewski MP, Meyer A, Hoffmann B, Aslan S \& Boos A 2011 Expression and functional implications of peroxisome proliferatoractivated receptor gamma (PPARgamma) in canine reproductive tissues during normal pregnancy and parturition and at antiprogestin induced abortion. Theriogenology 75 877-886. (doi:10.1016/j. theriogenology.2010.10.030)

Larcher A, Neculcea J, Breton C, Arslan A, Rozen F, Russo C \& Zingg HH 1995 Oxytocin receptor gene expression in the rat uterus during pregnancy and the estrous cycle and in response to gonadal steroid treatment. Endocrinology 136 5350-5356. (doi:10.1210/ en.136.12.5350)

Li XQ, Zhu P, Myatt L \& Sun K 2014 Roles of glucocorticoids in human parturition: a controversial fact? Placenta 35 291-296. (doi:10.1016/j. placenta.2014.03.005)

Magyar DM, Fridshal D, Elsner CW, Glatz T, Eliot J, Klein AH, Lowe KC, Buster JE \& Nathanielsz PW 1980 Time-trend analysis of plasma cortisol concentrations in the fetal sheep in relation to parturition. Endocrinology 107 155-159. (doi:10.1210/endo-107-1-155)

Mason JI, France JT, Magness RR, Murry BA \& Rosenfeld CR 1989 Ovine placental steroid 17 alpha-hydroxylase/C-17,20-lyase, aromatase and sulphatase in dexamethasone-induced and natural parturition. Journal of Endocrinology 122 351-359. (doi:10.1677/joe.0.1220351)

Meier S, Lau TM, Jenkin G \& Fairclough RJ 1995 Oxytocin-induced prostaglandin-F2-alpha release and endometrial oxytocin receptor concentrations throughout pregnancy in ewes. Journal of Reproduction and Fertility 103 233-238. (doi:10.1530/jrf.0.1030233)

Mparmpakas D, Zachariades E, Sotiriadis G, Goumenou A, Harvey AJ, Gidron Y \& Karteris E 2014 Differential expression of placental glucocorticoid receptors and growth arrest-specific transcript 5 in term and preterm pregnancies: evidence for involvement of maternal stress. Obstetrics and Gynecology International 2014239278. (doi:10.1155/2014/239278)

Nishiyama T, Tsumagari S, Ito M, Kimura J, Watanabe G, Taya K \& Takeishi M 1999 Immunohistochemical study of steroidogenic enzymes in the ovary and placenta during pregnancy in the dog. Anatomia, Histologia, Embryologia 28 125-129. (doi:10.1046/j.14390264.1999.00170.x)

Nnamani MC, Plaza S, Romero R \& Wagner GP 2013 Evidence for independent evolution of functional progesterone withdrawal in primates and guinea pigs. Evolution, Medicine, and Public Health 2013 273-288. (doi:10.1093/emph/eot022) 
Nohr B, Hoffmann B \& Steinetz BE 1993 Investigation of the endocrine control of parturition in the dog by application of an antigestagen. Journal of Reproduction and Fertility. Supplement 47 542-543.

Ojasoo T, Dore JC, Gilbert J \& Raynaud JP 1988 Binding of steroids to the progestin and glucocorticoid receptors analyzed by correspondenceanalysis. Journal of Medicinal Chemistry 31 1160-1169. (doi:10.1021/ jm00401a015)

Onclin K, Murphy B \& Verstegen JP 2002 Comparisons of estradiol, $\mathrm{LH}$ and $\mathrm{FSH}$ patterns in pregnant and nonpregnant beagle bitches. Theriogenology 57 1957-1972. (doi:10.1016/S0093691X(02)00644-1)

Philibert D, Costerousse G, Gaillardmoguilewsky M, Nedelec L, Nique F, Tournemine C \& Teutsch G 1991 From Ru-38486 towards dissociated antiglucocorticoid and antiprogesterone. Frontiers of Hormone Research 19 1-17. (doi:10.1159/issn.0301-3073)

Ratajczak CK \& Muglia LJ 2008 Insights into parturition biology from genetically altered mice. Pediatric Research 64 581-589. (doi:10.1203/ PDR.0b013e31818718d2)

Robinson RS, Mann GE, Lamming GE \& Wathes DC 2001 Expression of oxytocin, oestrogen and progesterone receptors in uterine biopsy samples throughout the oestrous cycle and early pregnancy in cows. Reproduction 122 965-979. (doi:10.1530/rep.0.1220965)

Schuler G, Hartung F \& Hoffmann B 1994 Investigations on the use of C-21-steroids as precursors for placental estrogen synthesis in the cow. Experimental and Clinical Endocrinology 102 169-174. (doi:10.1055/s 0029-1211278)

Schuler G, Ozalp GR, Hoffmann B, Harada N, Browne P \& Conley AJ 2006 Reciprocal expression of 17alpha-hydroxylase-C17,20-lyase and aromatase cytochrome P450 during bovine trophoblast differentiation: a two-cell system drives placental oestrogen synthesis. Reproduction 131 669-679. (doi:10.1530/rep.1.01033)

Smith VG, Edgerton LA, Hafs HD \& Convey EM 1973 Bovine serum estrogens, progestins and glucocorticoids during late pregnancy parturition and early lactation. Journal of Animal Science 36 391-396.
Sugimoto Y, Yamasaki A, Segi E, Tsuboi K, Aze Y, Nishimura T, Oida H, Yoshida N, Tanaka T, Katsuyama M et al. 1997 Failure of parturition in mice lacking the prostaglandin F receptor. Science 277 681-683. (doi:10.1126/science.277.5326.681)

Vermeirsch H, Simoens P \& Lauwers H 2000 Immunohistochemical detection of the estrogen receptor-alpha and progesterone receptor in the canine pregnant uterus and placental labyrinth. Anatomical Record 260 42-50. (doi:10.1002/(ISSN)1097-0185)

von der Ahe D, Janich S, Scheidereit C, Renkawitz R, Schutz G \& Beato M 1985 Glucocorticoid and progesterone receptors bind to the same sites in two hormonally regulated promoters. Nature 313 706-709. (doi:10.1038/313706a0)

Wu WX, Verbalis JG, Hoffman GE, Derks JB \& Nathanielsz PW 1996 Characterization of oxytocin receptor expression and distribution in the pregnant sheep uterus. Endocrinology 137 722-728. (doi:10.1210/ en.137.2.722)

Wyrwoll CS 2014 Developmental programming and the placenta: focusing in on glucocorticoids. Hormones, Intrauterine Health and Programming 12 17-26. (doi:10.1007/978-3-319-02591-9)

Zakar T \& Hertelendy F 2007 Progesterone withdrawal: key to parturition. American Journal of Obstetrics and Gynecology 196 289-296. (doi:10.1016/j.ajog.2006.09.005)

Zhang SM, Jonklaas J \& Danielsen M 2007 The glucocorticoid agonist activities of mifepristone (RU486) and progesterone are dependent on glucocorticoid receptor levels but not on EC50 values. Steroids 72 600-608. (doi:10.1016/j.steroids.2007.03.012)

Received 19 April 2016

First decision 4 May 2016

Revised manuscript received 9 June 2016

Accepted 4 July 2016 